\title{
Maximising data retention from the ISBSG repository
}

\author{
Kefu Deng and Stephen G. MacDonell \\ School of Computing and Mathematical Sciences, Auckland University of Technology \\ Private Bag 92006, Auckland 1142, New Zealand \\ smacdone@aut.ac.nz
}

\begin{abstract}
BACKGROUND: In 1997 the International Software Benchmarking Standards Group (ISBSG) began to collect data on software projects. Since then they have provided copies of their repository to researchers and practitioners, through a sequence of releases of increasing size.

PROBLEM: Questions over the quality and completeness of the data in the repository have led some researchers to discard substantial proportions of the data in terms of observations, and to discount the use of some variables in the modelling of, among other things, software development effort. In some cases the details of the discarding of data has received little mention and minimal justification.

METHOD: We describe the process we used in attempting to maximise the amount of data retained for modelling software development effort at the project level, based on previously completed projects that had been sized using IFPUG/NESMA function point analysis (FPA) and recorded in the repository.

RESULTS: Through justified formalisation of the data set and domain-informed refinement we arrive at a final usable data set comprising 2862 (of 3024) observations across thirteen variables.

CONCLUSION: a methodical approach to the pre-processing of data can help to ensure that as much data is retained for modelling as possible. Assuming that the data does reflect one or more underlying models, such retention should increase the likelihood of robust models being developed.
\end{abstract}

Empirical software engineering, ISBSG repository, data formalisation, effort prediction, regression, FPA

\section{INTRODUCTION AND MOTIVATION}

In order to understand and improve software engineering research and practice we must observe, measure (in a broad sense), record, analyse, interpret and act on data related to software engineering artefacts arising from software engineering activities. There has been particularly enduring interest in utilising such data for predictive modelling - that is, to use data from completed actions and artefacts to estimate the characteristics of future actions and artefacts. In fact, software engineering organisations have been encouraged (even implored) to implement and sustain software metrics programmes in order to systematise the above sequence.

Much of this work in research and practice has been directed to the prediction of software development effort, using the data collected from completed projects. The challenges of data collection and management for organisations practising software engineering are significant, however $[1,2]$. First, software projects tend to be long running processes - over months or years - hence completion is a relatively infrequent event. Second, some projects do not actually make it to completion, meaning that the data are either lost or not included in associated data sets. Third, project data are seen as commercially sensitive and therefore confidential, leading to reluctance to share information across organisational boundaries. Fourth, relatively few organisations devote sufficient effort to the systematic collection and organisation of project data. Finally, with fast changing technology, past project data can quickly become irrelevant in terms of future endeavours.

In order to provide software engineers with an alternative means of accessing such data several groups have positioned themselves as the keepers of repositories of data collected from multiple organisations. These repositories have been utilised extensively in research - many studies have reported using versions of the 'Finnish' data set [3] and the International Software Benchmarking Standards Group repository (ISBSG) [4] (for example, see [5-7]), among others. While commercial users are normally required to buy the latter repository, it is provided free to researchers on application. As a result, the ISBSG data set has been extensively used and cited by previous research. It is at present the largest multi-organization software engineering repository available. The data is collected using questionnaires in accordance with the benchmarking group's pre-defined terms and metrics, with records dating back to 1997 . These questionnaires enable the collection of data in a section-based structure that addresses: the Submitter, the Project, the Process, the Technology, the People and their Work Effort, the Product, the Project's Functional Size, and Project Completion. Further details can be found from the ISBSG website (isbsg.org), while some of the relevant details of the variables collected are discussed in later sections.

With respect to the ISBSG repository, however, questions over data quality and completeness have meant that much of the data potentially available has not actually been used in the analyses performed. For instance, all three primary studies reviewed by Kitchenham et al. [1] that had used the ISBSG repository had discarded data - in some instances significant proportions of the original data - if there were missing values in observations. While this step is sometimes mentioned, it is not always explained in detail - there seems to be a view that this is a 
necessary but relatively incidental element of data preparation. In other instances observations have been discarded if they did not have a sufficiently high ISBSG quality grade (see Section 2). (On submission, all of the information on a project is reviewed and rated in terms of data quality (A to D) by ISBSG experts. In particular, the experts look for omissions and inconsistencies in the data that might suggest that its reliability could be questioned.) This is a relatively 'blunt' approach to data set refinement. Furthermore, studies do not then consider the impact of such filtering on the population represented by the remaining observations. For the reader, if it is not clear what records have been discarded then it is difficult to know what the retained data actually represents.

Similarly, in spite of these software engineering repositories often comprising very large numbers of variables, the actual number of variables retained and used in the generated predictive models has generally been small. For example, the ISBSG data set contains more than 80 variables but just four were used in the final model generated in the work of Mendes et al. [8]. It is of course entirely reasonable to discard data in certain circumstances - as models get larger (in numbers of variables) they become increasingly intractable to build, and unstable to use. Furthermore, if accuracy is not significantly lower then a smaller model is normally to be preferred over a larger alternative, as in the main it would be easier to understand. However, the process of discarding data, as an important step in the data handling process, should be driven not just in response to missing values, or variables with lower correlation to the target variable, but also in relation to software engineering domain knowledge.

Bearing in mind the issues just described, it is contended here that the data selection/discarding process should be transparent and robust. That is, decisions taken with respect to data handling should have clearly stated and justified rationale, taking into account software engineering domain knowledge as well as indicators of statistical importance. Our specific interest here is in using such data for the early-phase prediction of full-project development effort. This paper therefore demonstrates a process through which the retention of data from a release of the ISBSG repository can be maximised with a view to supporting least-squares regression-based prediction of project effort based on previously completed projects sized using IFPUG/NESMA function point analysis (as a typical means of building prediction models).

The remainder of this paper is structured as follows. The next section outlines in general terms the use of the ISBSG repository in software engineering research, and provides a non-systematic illustration of the treatment of the repository in relation to data retention. The data analysis process undertaken for this research is reported in Section 3, comprising discussion and demonstration of the two steps of data set formalisation and refinement. The paper is then concluded in Section 4.

\section{RELATED WORK}

As stated above, the ISBSG repository has been used quite extensively as a data source for empirical software engineering research. A document available from the ISBSG website lists 44 past or ongoing research projects using the repository. (Note that the projects are listed up to 2007, and some known studies (including this one) are not included, so the true number is likely to be higher than 44.) A further rough indicator of the level of research activity utilising the repository can be drawn from the data returned from a query of Google Scholar - searching for "isbsg" returns 489 hits (as at March 2008), around 450 if citations are excluded. While this does also include items such as conference reports and calls for papers, a large proportion of these entries are published papers authored by those in the empirical software engineering research community.

We now consider a selection of these papers in addition to those reviewed in [1] and mentioned briefly above - but we acknowledge that this is a limited review. The intent is to provide an indicative sense of the various ways in which the repository data have been pre-processed by the research community, rather than a comprehensive discussion of all such treatments.

A study considering the influence of method and CASE tool usage on development effort using Release 8 of the ISBSG repository was reported by Cuadrado-Gallego and colleagues [9]. After starting with 2028 observations the researchers removed those will null or "invalid numerical values" for effort or size. Projects not sized using any of the FPA variants of interest were also removed. This appears to result in a data set of just under 1950 projects, although this is not stated. Clustering is then performed on the entire database, which we take to mean the 1950 projects clustered in two-dimensional space considering size (in function points) and effort. Mention is made of the removal of "a small number of outliers" but no further detail is given. Further analysis proceeds with much smaller data subsets corresponding to the use or non-use of methods and CASE tools.

Abran et al. [10] describe a comparison of approaches to building size-effort models for projects developed in a range of programming languages. They provide a useful description of the filtering required in order to utilise relevant data in their analysis. After starting with 789 records (from the 1999 release of the repository) they removed observations for small (lower effort) projects and those for which there was no data on the programming language used. They further removed observations for languages with two few samples to obtain significance, leaving a total sample of 371 records. In their modelling they used one predictor variable (having taken language into account) - size in function points. Further reduction of the data set after initial analysis involved the removal of 72 (undisclosed) outlier observations. 
A lesser degree of detail regarding data filtering (perhaps due to page restrictions) can be seen in the work of Adalier et al. [11]. The study begins with the 3024 observations available in Release 9 of the repository but immediately discards observations rated $B$ through $D$ for quality (in contrast to the Abran et al. study [10] which appears to treat all observations in the 1999 release as valid). Observations containing missing values are also dropped, resulting in a data set of 112 records. Of the many potential predictor variables available, only a function point count, source lines of code and normalised productivity rate are utilised. Of note in terms of effort estimation (rather than model fitting) is that the latter two are available only after a project has been completed.

Gencel and Buglione [12] cite the fact that the repository contains many nominal variables "on which mathematical operations cannot be carried out directly" as a rationale for splitting the data into subsets for processing in relation to the size-effort relationship for software projects. An alternative approach would be to treat such attributes as dummy variables in a single predictive model. On the basis of two prior studies, they took two such attributes into account - application type and business area type - but subsequently dropped the latter variable along with a measure of maximum team size because the values were "missing for most of the projects in ISBSG Release 10". They also utilised the quality ratings as a filter, retaining those observations rated $\mathrm{A}, \mathrm{B}$ or $\mathrm{C}$.

Only projects rated $A$ and $B$ were used in the analysis of Release 8 of the repository reported by Xia et al. [13]. Further filters were applied in relation to FPA-sizing method, development type, effort recording and availability of all of the components of function point counting (the fifteen unadjusted function point components and fourteen general system characteristics). All other variables appear to be discarded. As a result the original collection of 2027 records is reduced to a set of 184 for further processing.

The same quality rating filter is applied by Pendharkar et al. [14] in their use of the Release 7 iteration of the repository to investigate the link between team size and software size, and development effort. Further, they removed observations for which software size, team size or work effort values were missing. This led to the original set of 1238 project records being reduced to 540 observations.

Release 10 of the repository was used as the source of an analysis of the relationship between software size and development effort reported by Jiang et al. [15]. In this case only size in IFPUG/NESMA function points and effort in total hours are utilised. No 'quality' filtering is performed. Consequently a large proportion of records are retained for modelling -3433 of 4106 .

The above studies appear to reflect a general tendency to exclude many of the categorical variables from consideration, with analyses relying solely on one or a few indicators of software size. In some cases this is entirely justified, in that the other variables are simply not relevant to the issue at hand (e.g. in [14]), but in others it seems that potential difficulties in processing may have discouraged their use. In contrast, Sentas et al. [7] provide what is in our view the most comprehensive description of preparation and use of the ISBSG repository (and other data sets). Central to their work is the pre-processing of several categorical variables in the data set, addressing aspects such as the development platform and the application type. Their intent, as is also the case here, appears to be to keep for consideration as many variables as possible. A differentiating factor is their use of ordinal regression which is more readily able to consider categorical data. They then filter the data set based on quality ratings ( $A$ and $B$ only), FPA counting method (IFPUG), and aspects of effort recording. This led to a provisional data set of 556 observations (from 1239 (or 1238 [14]) in the release.) Their discarding of observations with missing values, however, saw more than 500 of these records removed, resulting in a data set of just 52 projects.

There is no question that missingness of data is a problem in empirical software engineering, as it is of course in other fields. "One of the problems often faced by statisticians undertaking statistical analysis in general, and multivariate analysis in particular, is the presence of missing data" [16]. It is commonly regarded as acceptable if the extent of missingness is small (for example, $5 \%$ or less) because it is normally inevitable to encounter missingness in the world of inferential statistics, which by its nature attempts to portray the characteristics of a population from those of an inherently incomplete sample. Furthermore, missingness becomes almost more inevitable (if there is such a thing!) when statistics are applied in a domain such as software engineering because the information being collected and analysed could be considered by submitters as commercially sensitive. The fact is that the majority of the observations in the ISBSG repository will contain missing values, due to the design of the data collection procedure and the nature of software engineering practice. For example, one of the data elements (or potential variables) collected in the ISBSG data set is the number of lines of software source code (LOC). If the sizing approach used for a particular project is IFPUG FPA, the LOC variable is purposely ignored. A further example is 'Organization Type' - some organisations might choose to ignore the associated data collection question for this variable in an effort to retain confidentiality (even though this is assured by the ISBSG).

A degree of missingness can be treated through the use of missing data techniques (MDTs) which attempt to impute the missing values, these methods having received some methodological attention in the empirical software engineering literature [17-19] and having been used in [8]. However, in order to be effective the degree of missingness needs to be less than a certain proportion of the potential data source - evidence to date suggests that $40 \%$ or $50 \%$ would be an upper limit for a data item in repository such as that provided by the ISBSG $[17,19]$. 
Finally we note here the work of Liebchen et al. [20] that specifically addressed the issue of data quality in software engineering data sets and the need to clean, filter and polish such data. We agree that greater attention needs to be directed to the pre-processing of data and concur with their view that such work has been limited to date.

\section{DATA ANALYSIS}

The particular version of the ISBSG repository used in this analysis is Release 9, made available between 2004 and 2007. It includes data on 3024 projects.

The data analysis process described here is composed of two major steps:

- Data Set Formalisation: Examination of the data reveals that it is neither appropriate nor sensible to perform ordinary least-squares (OLS) regression against the raw ISBSG repository as a whole. As a result, the raw ISBSG data set must be formalised to be of reasonable size and content. The rules and the rationale behind the data set formalisation are therefore explained.

- Data Set Further Refinement: Even when a formalised and 'full' data set is acquired, it is still not entirely appropriate to perform OLS regression analysis against it because of the intended objective of the prediction, the computational complexity of regression analysis and the expensiveness of acquiring project data for individual organizations. The methodology, rules and rationale of the data set further refinement process are explained in the second subsection.

\subsection{Data Set Formalisation}

Despite the fact that OLS regression is reasonably robust, the characteristics of the ISBSG repository mean that it is not feasible to perform an OLS regression analysis against the raw data set. Nor is this even advisable without some consideration of the need for pre-processing: cleaning, filtering and polishing the data [20], in light of the objectives of the particular analysis being undertaken, should always precede the analysis itself.

There are a number of issues related to the raw ISBSG data that require consideration and, in some cases, action:

- Some variables are de-normalized. Some of the variables in the raw ISBSG data set are simply descriptive strings rather than pre-defined categories. For example, for the variable 'Project Activity Scope', one observation reads: "Planning;Specification;Build;Test;Implement;" and another observation reads: "Specification;Build;Test;Implement;". This makes the number of distinct levels of the categorical variable very large and it is neither practical nor sensible to perform regression analysis against it. To make it (and other similar variables) usable in an OLS regression analysis, separate dummy variables have to be created with different levels of 'Project Activity Scope'.

- Some variables are not recorded in a consistent format. For example, in the variable 'Implementation Date', different formats exist for different observations, for instance "9-Nov-00" and "prior to Feb-2004". This makes it impossible for statistical software to recognize 'Implementation Date' as either a continuous or discrete variable.

- Some variables have too many distinct levels. The variable 'Application Type' comprises 105 different and distinct levels. If this categorical variable were to be included in a predictive regression model as is, 104 dummy variables would have to be included in the final equation.

- Some variables are a mixture of different contexts. For example, 'Development Techniques' in the raw ISBSG data set contains values such as "Waterfall" and "Object-oriented design". "Waterfall" is a generic development process model description whereas "Object-oriented design" is one of the activities undertaken if a project is implemented using object-oriented methods. Another example is the 'Intended Market' variable whose values inconsistently describe either the location of the development (whether developed in-house or externally) or the actual intended market (whether developed for an internal or external business unit).

- Some variables are aggregated from other variables. For example, the 'Adjusted Function Points' is calculated from variables such as 'Input Count', 'Output Count', and 'File Count'. Including both basic and aggregated variables contravenes the desire to have only necessary and orthogonal factors in a model.

- Some variables are irrelevant or unavailable for predictive modelling. Almost all of the observations in the repository were submitted after the relevant project was completed. As a result, some variables that are not known at the initialization/specification stage of projects are also included; for example, indicators of software quality ('Major Defects', 'Minor Defects'), 'Project Inactive Time' and some productivity variables.

- Some numerical variables have too few values. For example, 'Maximum Team Size' has 1918 records out of 3024 missing. In this case, even the best MDTs cannot be applied because this is far below the minimum proportion of non-missing value requirement for MDTs.

A straightforward solution to these issues would to drop the variables affected. In doing so, however, we may be throwing away predictive capability. Instead, some elements of the raw data set can be formalised through a range of variable transformations. Table 1 lays out the rationale for the formalisation of each variable in the raw ISBSG data set, with the variables shown in shaded boxes in column two being retained for further consideration. (Detailed descriptions of the variables can be found at the ISBSG website isbsg.org) Note that this represents a sample treatment of the data - a different formalisation may be applied if the research objective is different to the one of interest here (that is, estimation of project-level development effort). However, the underlying goal of data retention and adherence to the principle of transparent pre-processing still hold. 
TABLE 1: Formalisation rationale explained for variables in the raw ISBSG data set

\begin{tabular}{|c|c|c|}
\hline Raw ISBSG Variable & $\begin{array}{c}\text { Destination Variable } \\
\text { in Formalised Set }\end{array}$ & Rationale for the transformation \\
\hline Project ID & Project ID & No change - label. \\
\hline Data Quality Rating & Data Quality Rating & No change - could be used for later filtering. \\
\hline UFP rating & $\mathrm{N} / \mathrm{A}$ & Data quality indicator. Not directly related to software effort estimation. \\
\hline Count Approach & Count Approach & No change - will be used for later filtering. \\
\hline Functional Size & $\mathrm{N} / \mathrm{A}$ & $\begin{array}{l}\text { Only 'Adjusted Function Points' is used; this variable is a component of 'Adjusted } \\
\text { Function Points'. }\end{array}$ \\
\hline $\begin{array}{l}\text { Adjusted Function } \\
\text { Points }\end{array}$ & $\begin{array}{l}\text { Adjusted Function } \\
\text { Points }\end{array}$ & No change. \\
\hline Value Adjustment Factor & $N / A$ & $\begin{array}{l}\text { Only 'Adjusted Function Points' is used; this variable is a component of 'Adjusted } \\
\text { Function Points'. }\end{array}$ \\
\hline Summary Work Effort & Summary Work Effort & No change, the response variable. \\
\hline Normalised Work Effort & $\mathrm{N} / \mathrm{A}$ & $\begin{array}{l}\text { Only 'Summary Work Effort' is used; while potentially useful, the extrapolation } \\
\text { performed to produce this variable is arbitrarily applied and relies on 'Project Activity } \\
\text { Scope' being recorded, and recorded accurately. Median difference between } \\
\text { 'Summary Work Effort' and 'Normalised Work Effort' is zero. }\end{array}$ \\
\hline Reported PDR (afp) & $\mathrm{N} / \mathrm{A}$ & Unrelated to software effort estimation at the initialization phase of a project. \\
\hline Project PDR (ufp) & $\mathrm{N} / \mathrm{A}$ & Unrelated to software effort estimation at the initialization phase of a project. \\
\hline Normalised PDR (afp) & $\mathrm{N} / \mathrm{A}$ & Unrelated to software effort estimation at the initialization phase of a project. \\
\hline Normalised PDR (ufp) & $\mathrm{N} / \mathrm{A}$ & Unrelated to software effort estimation at the initialization phase of a project. \\
\hline Project Elapsed Time & $\mathrm{N} / \mathrm{A}$ & Unrelated to software effort estimation at the initialization phase of a project. \\
\hline Project Inactive Time & $\mathrm{N} / \mathrm{A}$ & Unrelated to software effort estimation at the initialization phase of a project. \\
\hline Implementation Date & $\begin{array}{l}\text { 'Implementation Start } \\
\text { Year' and } \\
\text { 'Implementation Start } \\
\text { Year Range' }\end{array}$ & $\begin{array}{l}\text { Potentially unrelated to software effort estimation at the initialization phase of a } \\
\text { project. The raw data set is not in constant format. Furthermore, about } 20 \% \text { of the } \\
\text { data are missing. Review data and form two variables (details below). }\end{array}$ \\
\hline Project Activity Scope & $\mathrm{N} / \mathrm{A}$ & $\begin{array}{l}\text { De-normalised, providing too much information in one variable. Moreover, this data is } \\
\text { primarily useful in terms of determining 'Normalised Work Effort', a variable that is } \\
\text { not to be retained in this case. }\end{array}$ \\
\hline Effort Plan & $\mathrm{N} / \mathrm{A}$ & $\begin{array}{l}\text { Only 'Summary Work Effort' is used; furthermore (i) this can be expensive to get for } \\
\text { software organisations and (ii) there could be some question over its accuracy. }\end{array}$ \\
\hline Effort Specify & $\mathrm{N} / \mathrm{A}$ & Same as previous. \\
\hline Effort Design & $\mathrm{N} / \mathrm{A}$ & Same as previous. \\
\hline Effort Build & $\mathrm{N} / \mathrm{A}$ & Same as previous. \\
\hline Effort Test & $\mathrm{N} / \mathrm{A}$ & Same as previous. \\
\hline Effort Implement & $\mathrm{N} / \mathrm{A}$ & Same as previous. \\
\hline Effort Unphased & $\mathrm{N} / \mathrm{A}$ & Same as previous. \\
\hline Minor defects & $\mathrm{N} / \mathrm{A}$ & Unrelated to software effort estimation at the initialization phase of a project. \\
\hline Major defects & $\mathrm{N} / \mathrm{A}$ & Same as previous. \\
\hline Extreme defects & $\mathrm{N} / \mathrm{A}$ & Same as previous. \\
\hline Total Defects Delivered & $\mathrm{N} / \mathrm{A}$ & Same as previous. \\
\hline Development Type & Development Type & No change. \\
\hline Organisation Type & $N / A$ & $\begin{array}{l}\text { Too many (more than 100) distinct levels. Mixed in context with 'Application Type' } \\
\text { and 'Business Area Type'. This could involve some level of arbitrariness. }\end{array}$ \\
\hline Business Area Type & Business Area Type & $\begin{array}{l}\text { Re-categorize missing values to "Unspecified" and rename the labels according to } \\
\text { standard sector descriptors (details below). }\end{array}$ \\
\hline Application Type & $\mathrm{N} / \mathrm{A}$ & Same issues as for 'Organisation Type', therefore it is omitted \\
\hline Package Customisation & $\begin{array}{l}\text { Package } \\
\text { Customisation }\end{array}$ & $\begin{array}{l}\text { Formalise "Unknown" and missing values in the raw data to "Unspecified" (details } \\
\text { below). }\end{array}$ \\
\hline Degree of Customisation & $\mathrm{N} / \mathrm{A}$ & Too many missing values (2937 out of $3024,97 \%$ ) and too many distinct levels (19). \\
\hline Architecture & Architecture & $\begin{array}{l}\text { Re-categorize missing values to "Unspecified" and rename the levels according to } \\
\text { current mainstream standards (details below). }\end{array}$ \\
\hline Client Server? & $\mathrm{N} / \mathrm{A}$ & Too many missing values (1346 out of $3024,45 \%)$. Considered in 'Architecture'. \\
\hline Client roles & $\mathrm{N} / \mathrm{A}$ & Too many missing values ( 2968 out of $3024,98 \%$ ). \\
\hline Server roles & $\mathrm{N} / \mathrm{A}$ & Too many missing values ( 2970 out of $3024,98 \%)$. \\
\hline Type of server & $\mathrm{N} / \mathrm{A}$ & Too many missing values ( 2821 out of $3024,93 \%$ ). \\
\hline Client/server description & $\mathrm{N} / \mathrm{A}$ & $\begin{array}{l}\text { Too many missing values (2291 out of 3024, 76\%). Considered in 'Architecture' and } \\
\text { 'Web development' }\end{array}$ \\
\hline Web development & Is Web & Re-categorize missing values to "Unspecified" (details below) \\
\hline Plan documents & $\mathrm{N} / \mathrm{A}$ & Too many missing values (2896 out of $3024,96 \%$ ). \\
\hline Specify documents & $\mathrm{N} / \mathrm{A}$ & Too many missing values (2897 out of $3024,96 \%)$. \\
\hline Specify techniques & $\mathrm{N} / \mathrm{A}$ & Too many missing values ( 2961 out of $3024,98 \%$ ). \\
\hline Design documents & $\mathrm{N} / \mathrm{A}$ & Too many missing values ( 2907 out of $3024,96 \%$ ). \\
\hline Design techniques & $\mathrm{N} / \mathrm{A}$ & Too many missing values ( 2970 out of $3024,98 \%)$. \\
\hline Build products & $\mathrm{N} / \mathrm{A}$ & Too many missing values ( 2895 out of $3024,96 \%)$. \\
\hline Build activity & $\mathrm{N} / \mathrm{A}$ & Too many missing values ( 2951 out of $3024,98 \%$ ). \\
\hline Test documents & $\mathrm{N} / \mathrm{A}$ & Too many missing values ( 2896 out of $3024,96 \%$ ). \\
\hline Test activity & $\mathrm{N} / \mathrm{A}$ & Too many missing values (2984 out of $3024,99 \%)$. \\
\hline Implement documents & $\mathrm{N} / \mathrm{A}$ & Too many missing values (2909 out of $3024,96 \%)$. \\
\hline Implement activity & $\mathrm{N} / \mathrm{A}$ & Too many missing values ( 2957 out of $3024,98 \%$ ). \\
\hline $\begin{array}{l}\text { Development } \\
\text { Techniques }\end{array}$ & $\begin{array}{l}\text { 'Main Development } \\
\text { Process Model' and } \\
\text { 'Object Orientation' }\end{array}$ & $\begin{array}{l}\text { Too many different contexts are explained in this one variable. In this case, two } \\
\text { variables are extracted from the raw variable with formalised values (details below). }\end{array}$ \\
\hline $\begin{array}{l}\text { Functional Sizing } \\
\text { Technique }\end{array}$ & $\mathrm{N} / \mathrm{A}$ & Unrelated to software effort estimation at the initialization phase of a project. \\
\hline FP Standard & $\mathrm{N} / \mathrm{A}$ & Same as previous. \\
\hline FP Standards all & $\mathrm{N} / \mathrm{A}$ & Same as previous. \\
\hline
\end{tabular}




\begin{tabular}{|c|c|c|}
\hline $\begin{array}{l}\text { Reference Table } \\
\text { Approach }\end{array}$ & $\mathrm{N} / \mathrm{A}$ & Same as previous. \\
\hline Development Platform & Development Platform & Re-categorize missing values to "Unspecified" (details below). \\
\hline Language Type & Main Language Type & Re-categorize missing values to "Unspecified" (details below). \\
\hline $\begin{array}{l}\text { Primary Programming } \\
\text { Language }\end{array}$ & $\mathrm{N} / \mathrm{A}$ & $\begin{array}{l}\text { Mixture of contexts. For example some values are "3GL" or " } 4 \mathrm{GL} \text { " which is language } \\
\text { type and some others are "IIS" which is the name of a type of web server. Some } \\
\text { values have version numbers while some others do not. In such a case, it is very } \\
\text { hard to get a sensible category from this variable. Furthermore, given the "Language } \\
\text { Type' the specific programming language cannot provide too much extra information. }\end{array}$ \\
\hline 1st Hardware & $\mathrm{N} / \mathrm{A}$ & $\begin{array}{l}\text { Mixture of contexts. For example: "Client/Server", "Unix" ... which are not } \\
\text { descriptions of hardware. }\end{array}$ \\
\hline 1st Operating System & $\begin{array}{l}\text { Main Operating } \\
\text { System }\end{array}$ & $\begin{array}{l}\text { Distinct values in raw dataset to be extracted and re-categorized. Levels are } \\
\text { minimized according to the mainstream operating systems (details below). }\end{array}$ \\
\hline 1st Language & $\mathrm{N} / \mathrm{A}$ & Same as for 'Primary Programming Language'. \\
\hline 1st Data Base System & $\begin{array}{l}\text { Main Database } \\
\text { System }\end{array}$ & Same rationale and process as for 'Main Operating System' (details below). \\
\hline 1st Component Server & $\mathrm{N} / \mathrm{A}$ & Too many missing values (3001 out of $3024,99 \%)$. \\
\hline 1st Web Server & $\mathrm{N} / \mathrm{A}$ & Too many missing values (3003 out of $3024,99 \%)$. \\
\hline 1st Message Server & $\mathrm{N} / \mathrm{A}$ & Too many missing values ( 3017 out of $3024,100 \%)$. \\
\hline 1st Debugging tool & $\mathrm{N} / \mathrm{A}$ & Too many missing values ( 2786 out of $3024,92 \%)$. \\
\hline 1st Other Platform & $\mathrm{N} / \mathrm{A}$ & Too many missing values ( 2189 out of $3024,72 \%$ ). \\
\hline 2nd Hardware & $\mathrm{N} / \mathrm{A}$ & Too many missing values (3024 out of $3024,100 \%$ ). \\
\hline 2nd Operating System & $\mathrm{N} / \mathrm{A}$ & Too many missing values (2995 out of $3024,99 \%)$. \\
\hline 2nd Language & $\mathrm{N} / \mathrm{A}$ & Too many missing values (2963 out of $3024,98 \%$ ). \\
\hline 2nd Data Base System & $\mathrm{N} / \mathrm{A}$ & Too many missing values (3009 out of $3024,100 \%)$. \\
\hline 2nd Component Server & $\mathrm{N} / \mathrm{A}$ & Too many missing values ( 3022 out of $3024,100 \%)$. \\
\hline 2nd Web Server & $\mathrm{N} / \mathrm{A}$ & Too many missing values (3023 out of $3024,100 \%)$. \\
\hline 2nd Message Server & $\mathrm{N} / \mathrm{A}$ & Too many missing values (3022 out of $3024,100 \%)$. \\
\hline 2nd Other Platform & $\mathrm{N} / \mathrm{A}$ & Too many missing values (2993 out of $3024,99 \%)$. \\
\hline CASE Tool Used & Case Tool Used & Re-categorize missing values to "Unspecified" (details below). \\
\hline Used Methodology & $\mathrm{N} / \mathrm{A}$ & Unrelated to software effort estimation at the initialization phase of a project. \\
\hline $\begin{array}{l}\text { How Methodology } \\
\text { Acquired }\end{array}$ & $\mathrm{N} / \mathrm{A}$ & Same as previous. \\
\hline $\begin{array}{l}\text { User Base - Business } \\
\text { Units }\end{array}$ & $N / A$ & Too many missing values (2434 out of $3024,80 \%$ ). \\
\hline User Base - Locations & $\mathrm{N} / \mathrm{A}$ & Too many missing values ( 2384 out of $3024,79 \%$ ). \\
\hline $\begin{array}{l}\text { User Base - Concurrent } \\
\text { Users }\end{array}$ & $\mathrm{N} / \mathrm{A}$ & Too many missing values (2408 out of $3024,80 \%$ ). \\
\hline Intended Market & $\begin{array}{l}\text { 'Developed Inhouse' } \\
\text { and 'Intended Market' }\end{array}$ & $\begin{array}{l}\text { The 'Intended Market' in the raw ISBSG dataset explains two aspects of the software } \\
\text { development process. One is the location where the project is developed. Another is } \\
\text { the actual intended market. Here the variable is separated (details below). }\end{array}$ \\
\hline Recording Method & $\mathrm{N} / \mathrm{A}$ & Unrelated to software effort estimation at the initialization phase of a project. \\
\hline Resource Level & $\mathrm{N} / \mathrm{A}$ & Unrelated to software effort estimation at the initialization phase of a project. \\
\hline Max Team Size & $\mathrm{N} / \mathrm{A}$ & Too many missing values (1836 out of $3024,61 \%)$. \\
\hline Average Team Size & $\mathrm{N} / \mathrm{A}$ & Too many missing values ( 1918 out of $3024,63 \%)$. \\
\hline $\begin{array}{l}\text { Ratio of Project Effort: } \\
\text { non-project Effort }\end{array}$ & $\mathrm{N} / \mathrm{A}$ & Unrelated to software effort estimation at the initialization phase of a project. \\
\hline $\begin{array}{l}\text { \% of uncollected Work } \\
\text { Effort }\end{array}$ & $\mathrm{N} / \mathrm{A}$ & Unrelated to software effort estimation at the initialization phase of a project. \\
\hline Input count & $N / A$ & $\begin{array}{l}\text { An element of the 'Adjusted Function Points' already included. This variable does no } \\
\text { provide additional value given the focus of most studies on project-level estimation. }\end{array}$ \\
\hline Output count & $\mathrm{N} / \mathrm{A}$ & Same as previous. \\
\hline Enquiry count & $\mathrm{N} / \mathrm{A}$ & Same as previous. \\
\hline File count & $\mathrm{N} / \mathrm{A}$ & Same as previous. \\
\hline Interface count & $\mathrm{N} / \mathrm{A}$ & Same as previous. \\
\hline Added count & $\mathrm{N} / \mathrm{A}$ & Same as previous. \\
\hline Changed count & $\mathrm{N} / \mathrm{A}$ & Same as previous. \\
\hline Deleted count & $\mathrm{N} / \mathrm{A}$ & Same as previous. \\
\hline Lines of code & $\mathrm{N} / \mathrm{A}$ & $\begin{array}{l}\text { Lines of code approach, an alternative sizing method, is not included in the research } \\
\text { target. Unrelated to software effort estimation at the initialization phase of a project. }\end{array}$ \\
\hline LOC not Statements & $\mathrm{N} / \mathrm{A}$ & Same as previous. \\
\hline
\end{tabular}

Table 2 lists the variables drawn from the raw ISBSG data set that comprise the 'full' scope from which further variable selection could be reasonably undertaken. For each of the (reordered) variables, the type of the variable (continuous, ordinal or categorical) and the distinct levels of the categorical variables are listed. The extraction of these variables is informed by the information available in the ISBSG data set and ISBSG supplied demographics as well as by prior studies and the intended analyses in terms of project-level prediction.

Once the set of candidate variables has been selected, a rule is defined in order to actually perform the data set formalisation. Before establishing the rules, each distinct value for each of the retained variables in the raw ISBSG data set is carefully examined in order to minimize confusion of concepts and to maximize both consistency and numbers of responses for each level. During the formalisation process, missing or ambiguous categorical values are treated as "Unspecified". As the whole process of defining the formalisation rules is manual, some of the definitions and rules could be considered to be arbitrary. However, significant effort has been expended in an effort to ensure that each decision is defendable and each rule applied consistently. Furthermore, it is contended here 
that retaining data, even if achieved using potentially arbitrary rules, is to be preferred over the similarly arbitrary dropping of those significant numbers of observations that have missing values. Such a decision would see a very large proportion of the data dropped - observations without missing values in the estimation-related variables account for just $20 \%$ of the data. The formalisation rules and their rationale are shown in Table 3.

TABLE 2: Extracted candidate variables from the ISBSG data set as the 'full' data set

\begin{tabular}{|l|l|l|}
\hline Candidate Variable & Variable Type & Notes \\
\hline Project ID & Nominal & The unique identifier of the project being described. \\
\hline Adjusted Function Points & Continuous & $\begin{array}{l}\text { Data is complete. The function point value of each project must be included for all } \\
\text { projects using this as a counting approach. }\end{array}$ \\
\hline Development Type & Categorical & Data is complete, all levels for this variable are provided. \\
\hline Business Area Type & Categorical & $\begin{array}{l}\text { Levels: Health, Insurance, Banking, IT \& T, Manufacturing, Accounting, Transport, } \\
\text { Government, Sales and Marketing, Other, Unspecified }\end{array}$ \\
\hline Package Customisation & Categorical & Levels: Yes, No, Unspecified \\
\hline Developed Inhouse & Categorical & Levels: Yes, No, Partly, Unspecified \\
\hline Intended Market & Categorical & Levels: Internal, External, Both, Unspecified \\
\hline Implementation Start Year & Ordinal & But no validity in its use as a numeric predictor. \\
\hline Implementation Start Year Range & Categorical & Levels: 1989-1994, 1995-1999, 2000-2004, Unspecified. \\
\hline Architecture & Categorical & Levels: Stand Alone, Multi Tier, Client Server, Unspecified \\
\hline Is Web & Categorical & Levels: Yes, Unspecified \\
\hline Development Platform & Categorical & Levels: PC, Mid-range, Main-frame, Multi-platform, Unspecified \\
\hline Main Language Type & Categorical & Levels: 2 GL, 3GL, 4GL, 5GL, APG, Unspecified \\
\hline Main Database System & Categorical & Levels: Oracle, DB2, SQL Server, Other, Unspecified \\
\hline Main Operating System & Categorical & Levels: Mainframe, DOS, Windows, Solaris, Unix, Other, Unspecified \\
\hline CASE Tool Used & Categorical & Levels: Yes, No, Don't know, Unspecified \\
\hline Main Development Process Model & Categorical & Levels: Waterfall, Iterative, Other, Unspecified \\
\hline Object Orientation & Categorical & Levels: Yes, Unspecified \\
\hline Summary Work Effort & Continuous & The response, with the unit 'person hours'. \\
\hline
\end{tabular}

TABLE 3: Formalisation rules applied to the raw ISBSG data set

\begin{tabular}{|c|c|c|}
\hline Formalised Variable & Formalisation Rule & Rationale of the Formalisation \\
\hline Adjusted Function Points & No change & $\begin{array}{l}\text { No change needed as the variable is compuls orily required } \\
\text { by ISBSG for FPA-based records. }\end{array}$ \\
\hline Development Type & No change & $\begin{array}{l}\text { No change needed as the variable is complete and has only } \\
4 \text { distinct levels. }\end{array}$ \\
\hline Business Area Type & See Note 1 below & $\begin{array}{l}\text { This variable is a mixture of organisation type, application } \\
\text { type and business area type. Detailed formalisation rules } \\
\text { are utilised, explained in brief below to form } 11 \text { levels. }\end{array}$ \\
\hline Package Customisation & $\begin{array}{l}\text { Same as 'Package Customisation'. If the value is } \\
\text { "Don't know" or null then "Unspecified" }\end{array}$ & $\begin{array}{l}\text { To make it more appropriate for regression analysis by } \\
\text { categorising empty data into a value called "Unspecified". }\end{array}$ \\
\hline Developed Inhouse & See Table 4 'Intended Market' & $\begin{array}{l}\text { The 'Intended Market' variable addresses two aspects of the } \\
\text { software development process. One is the type of the } \\
\text { physical location in which the project is developed, the other } \\
\text { is the actual intended market. This variable specifies "type } \\
\text { of the physical location where the project is developed". }\end{array}$ \\
\hline Intended Market & See Table 4 'Intended Market' & $\begin{array}{l}\text { This variable addresses the actual intended market as } \\
\text { indicated from the original variable 'Intended Market' by } \\
\text { stripping off the information regarding 'Developed Inhouse' } \\
\text { (Please see previous row for more information.) }\end{array}$ \\
\hline $\begin{array}{l}\text { Implementation Start } \\
\text { Year }\end{array}$ & $\begin{array}{l}\text { Manually convert 'Implementation Date' to the } \\
\text { specified year e.g. "24/03/1999" to } 1999\end{array}$ & $\begin{array}{l}\text { Manually extract the year because values need to conform } \\
\text { to a constant format. (Used only to determine next variable.) }\end{array}$ \\
\hline $\begin{array}{l}\text { Implementation Start } \\
\text { Year Range }\end{array}$ & $\begin{array}{l}\text { Convert 'Implementation Start Year' to the } \\
\text { appropriate year range: } 1989-1994,1995-1999, \\
2000-2004\end{array}$ & $\begin{array}{l}\text { There are more than } 500 \text { missing values out of } 2800 \\
\text { observations in 'Implementation Start Year'. Furthermore, } \\
\text { while it might be useful in terms of time series analysis it is } \\
\text { not sensible to use start year as a numeric predictor } \\
\text { variable. Given that the variable may have potential worth a } \\
\text { categorical version can be included. }\end{array}$ \\
\hline Architecture & See Table 5 'Architecture' & \\
\hline Is Web & $\begin{array}{l}\text { If 'Web Development' is "Web" then "Yes" else } \\
\text { "Unspecified" }\end{array}$ & $\begin{array}{l}\text { The raw data set only contains "Yes" and null values for this } \\
\text { variable. If the value is null, no assumption can be made } \\
\text { about the project, thus "Unspecified" is used in its place. }\end{array}$ \\
\hline Development Platform & $\begin{array}{l}\text { Same as 'Development Platform'. If the value is } \\
\text { null then "Unspecified" }\end{array}$ & \\
\hline Main Language Type & $\begin{array}{l}\text { Same as 'Language Type'. If the value is null } \\
\text { then "Unspecified" }\end{array}$ & \\
\hline Main Database System & $\begin{array}{l}\text { If 'First Database System' contains "Oracle" then } \\
\text { "Oracle" } \\
\text { else If 'First Database System' contains "DB2" } \\
\text { then "DB2" } \\
\text { else If 'First Database System' contains "SQL } \\
\text { Server" OR "SQL-Server" OR "MS SQL" OR } \\
\text { "MSDE" then "MS SQL" } \\
\text { else If 'First Database System' is null then } \\
\text { "Unspecified" } \\
\text { else "Other" }\end{array}$ & Same reasoning as for 'Main Operating System'. \\
\hline
\end{tabular}




\begin{tabular}{|c|c|c|}
\hline Main Operating System & $\begin{array}{l}\text { If 'First Operating System' contains "Windows" } \\
\text { OR "win" OR “.net" OR "SQL-server" OR "NT } \\
\text { Server" OR "NT" OR "XP" then "Windows" } \\
\text { else If 'First Operating System' contains } \\
\text { "Mainframe" then "Mainframe" } \\
\text { else If 'First Operating System' contains "DOS" } \\
\text { then "DOS" } \\
\text { else If 'First Operating System' contains "Solaris" } \\
\text { then "Solaris" } \\
\text { else If 'First Operating System' contains "Unix" } \\
\text { then "Unix" } \\
\text { else if 'First Operating System' is null OR } \\
\text { contains "client/server" OR "custom" OR "not } \\
\text { assessed" OR "not recorded" then "Unspecified" } \\
\text { else "Other" }\end{array}$ & $\begin{array}{l}\text { Distinct values in the raw data set are extracted and re- } \\
\text { categorised. The levels are minimized according to the } \\
\text { mainstream software development operating systems. }\end{array}$ \\
\hline CASE Tool Used & $\begin{array}{l}\text { Same as 'Case Tool Used'. If the value is null } \\
\text { then "Unspecified" }\end{array}$ & \\
\hline $\begin{array}{l}\text { Main Development } \\
\text { Process Model }\end{array}$ & $\begin{array}{l}\text { If 'Development Techniques' contains "Waterfall" } \\
\text { then "Waterfall" } \\
\text { else If 'Development Techniques' contains } \\
\text { "RAD" OR "Rapid Application Development" OR } \\
\text { "Prototype" then "Iterative" } \\
\text { else If 'Development Techniques' is null then } \\
\text { "Unspecified" } \\
\text { else "Other" }\end{array}$ & $\begin{array}{l}\text { 'Development Techniques' in the raw data set is a mixture of } \\
\text { 'Main Development Process Model' and 'Object Orientation' } \\
\text { which are two entirely different kinds of context with different } \\
\text { criteria. Some of the values are actually explaining the } \\
\text { detailed steps/activities in software development processes } \\
\text { rather than the development process on its own. }\end{array}$ \\
\hline Object Orientation & $\begin{array}{l}\text { If “Development Techniques' contains "Object } \\
\text { oriented" OR "Object-oriented" OR "OO" then } \\
\text { "Yes" } \\
\text { else "Unspecified" }\end{array}$ & \\
\hline Summary Work Effort & Same as 'Summary Work Effort' & \\
\hline
\end{tabular}

Note 1: Due to constraints on space it is not possible to replicate here the table that details the formalisation of 'Business Area Type', which shows the transformation of nearly 100 non-standard descriptions to standard business sector labels. The following examples should illustrate the process and outcomes, however: Telecommunications, Computer Systems and IT, Network card administration were all formalised as "IT \& T"; and Product Distribution, TRANSPORT and Transport/Shipping were all formalised as "Logistics".

The two tables following ( 4 and 5) define the specific formalisation rules for raw variables 'Intended Market' and 'Architecture' based on the principles described in Table 3. Note that instances of 'Intended Market' with the value "Multi-tier/Client server" are coded to the more complex "Multi Tier" value in the formalised version of the data set, to ensure that the potential complexity is accounted for (as it is considered preferable to be conservative).

TABLE 4: Formalisation rules applied to 'Intended Market' in the raw ISBSG data set

\begin{tabular}{|l|l|l|}
\hline Raw ISBSG Values(Intended Market) & $\begin{array}{l}\text { Formalised ISBSG Values } \\
\text { (Developed Inhouse) }\end{array}$ & $\begin{array}{l}\text { Formalised ISBSG Values } \\
\text { (Intended Market) }\end{array}$ \\
\hline Outsourced for internal business unit & No & Internal \\
\hline Customer \& users 1 org, team in another & No & External \\
\hline Customer, users, team in different orgs & No & External \\
\hline In-house for internal business unit & Yes & Internal \\
\hline Partly outsourced and partly inhouse & Partly & Partly \\
\hline Customer, users \& team in same org & Yes & Internal \\
\hline In-house for all internal business units & Yes \\
\hline Customer \& team 1 org, users in another & Yes & Internal \\
\hline In-house for external business unit & Yes & External \\
\hline In-house for internal business unit; In-house for external business unit & Yes & Both \\
\hline Dev in-house for use by ext agent req to rept to us & Yes & External \\
\hline External for external business unit & No & Yes \\
\hline Inhouse for bank customers & Unspecified \\
\hline NULL (value is missing) & Internal \\
\hline
\end{tabular}

TABLE 5: Formalisation rules applied to 'Architecture' in the raw ISBSG data set

\begin{tabular}{|l|l|}
\hline Raw ISBSG Values & Formalised ISBSG Values \\
\hline Multi-tier / Client server & Multi Tier \\
\hline Multi-tier & Multi Tier \\
\hline Multi-tier with web public interface & Multi Tier \\
\hline Stand alone & Stand Alone \\
\hline Client server & Client Server \\
\hline NULL (value is missing) & Unspecified \\
\hline
\end{tabular}

At the conclusion of the formalisation process the data set comprises one label variable (Project ID), one response variable (Summary Work Effort) and 16 potential predictor variables, with 2862 complete records (i.e. records for IFPUG/NESMA FPA-sized projects, with no missing values). 


\subsection{Further Refinement of the Data Set}

To this point, all the appropriate and potentially useful variables and observations in terms of project-level software effort estimation have been pre-processed from the raw ISBSG data. Some values have been modified with justification in order to produce sound categorical variables for regression analysis and/or to deal with missing values. The result is a formalised and 'full' data set created from the raw ISBSG data repository. The following issues then need to be considered:

- Taking into account the principles and conventions of software engineering, it is not meaningful to include some of the available variables in an effort estimation model. Weisberg [21] argued that "the single most important tool in selecting a subset of variables for use in a model is the analyst's knowledge of the substantive area under study." He then criticised the action of including all variables in multiple regression models as "throwing everything in the hopper" simply because they are available.

- It is also difficult to make statistical inference from an overly-complicated regression model because it becomes difficult to explain and anticipate the impact of the overall model given certain input conditions. As a result the model may be problematic to utilize in a production environment. It is also difficult to explain the relationship between the response and the many independent variables, given that there may be interaction effects among the independent variables.

- The calculation of a regression model can be computationally expensive. To illustrate, if all 16 predictor variables with all the interactions were to be included in a model, the number of potential components in the final model equation could be $(15 !+1)$. Formulating such a model over the potentially large number of observations (in this case a data comprising more then 2800 observations) would challenge the processing limitations of current desktop PCs.

While there is no definitive suggestion as to the maximum number of candidate variables that should exist in a full data set, there is an accepted trade off between accuracy and parsimony. Finding an optimum model should be informed by software engineering principles and relevant personal experience. With this in mind, all the variables retained so far are considered to decide whether they should be kept in the full data set for further study. Two principles inform the decision to keep or drop a variable at this point:

1. A variable should be dropped if too great a degree of effort has to be expended in order to decide the value of it in the process of software/systems development, given that estimates of effort are often first needed in the very early stages of development

2. A variable should be dropped if there is no conceptual justification for its contribution to a predictive model of software development effort.

In light of the above Table 6 describes the relevant 'Keep/Drop' decisions and the rationale for each, for the 16 potential predictors.

TABLE 6: Final decisions regarding retention of potential predictor variables

\begin{tabular}{|c|c|c|}
\hline Variable & Action & Explanation \\
\hline $\begin{array}{l}\text { Adjusted Function } \\
\text { Points }\end{array}$ & Keep & Indicator of project scale. Available quite early, prior evidence of relationship with effort. \\
\hline Development Type & Keep & Indicator of project type. Available early, prior evidence of relationship with effort. \\
\hline Business Area Type & Keep & Indicator of project domain. Available early, prior evidence of relationship with effort. \\
\hline $\begin{array}{l}\text { Package } \\
\text { Customization }\end{array}$ & Keep & Indicator of project type. Available early, possibly related to effort. \\
\hline Developed Inhouse & Keep & Indicator of project structure. Available early, possibly related to effort. \\
\hline Intended Market & Keep & Indicator of project structure. Available early, possibly related to effort. \\
\hline $\begin{array}{l}\text { Implementation Start } \\
\text { Year Range }\end{array}$ & Keep & Indicator of project context. Can be estimated early, possibly related to effort. \\
\hline Architecture & Drop & $\begin{array}{l}\text { In reality, software developers can expend substantial effort in order to reach a decision as to which } \\
\text { architecture to use, by investigating the solution domain and the availability of current technology. } \\
\text { Therefore, at the time when effort estimates are first needed, decision makers may not have decided on } \\
\text { the architecture to use. }\end{array}$ \\
\hline Is Web & Drop & $\begin{array}{l}\text { The levels of this variable are only "Yes" and "Unspecified". In reality, a project could be a combination } \\
\text { of web and other types depending on the chosen architecture. }\end{array}$ \\
\hline Development Platform & Keep & Indicator of project technology. Available early, possibly related to effort. \\
\hline Main Language Type & Keep & Indicator of project technology. Available quite early, possibly related to effort. \\
\hline $\begin{array}{l}\text { Main Operating } \\
\text { System }\end{array}$ & Keep & Indicator of project technology. Available quite early, possibly related to effort. \\
\hline $\begin{array}{l}\text { Main Database } \\
\text { System }\end{array}$ & Drop & $\begin{array}{l}\text { To make the decision as to which database system to use, a significant amount of effort would normally } \\
\text { be expended. For example, comparing the performance capabilities, benchmarking and proof-of- } \\
\text { concept documentation. In reality, organisations tend to favour one or more particular DB systems (as } \\
\text { per Architecture) but even this varies over time and (for bespoke systems) depends on customer needs. }\end{array}$ \\
\hline CASE Tool Used & Keep & Indicator of project technology. Available quite early, possibly related to effort. \\
\hline $\begin{array}{l}\text { Main Development } \\
\text { Process Model }\end{array}$ & Keep & Indicator of project process. Available early, possibly related to effort. \\
\hline Object Orientation & Drop & This decision would normally be made at the design phase. \\
\hline
\end{tabular}

This step represents the end of the data set refinement process. At this point there exists a refined data set that is usable in terms of OLS regression analysis, comprising one continuous response variable and twelve predictor variables (one continuous and eleven categorical). In our processing of Release 9 of the ISBSG repository this resulted in the provision of a complete data set still including 2862 observations, comprising 673 rated A quality, 2006 rated $B, 106$ rated $C$ and 77 rated $D$. 


\section{CONCLUSIONS}

We believe that there is a need for greater clarity in describing and justifying the pre-processing, discarding and retention of data from software engineering data sets. In this paper we have illustrated how such clarity can be achieved through an example, filtering, formalising and refining the data in Release 9 of the ISBSG repository in line with an intent to build a predictive model of project-level development effort for FPA-sized projects.

Note that the above outcomes in terms of the variables retained or discarded are not intended to be conveyed as 'correct'. Rather, it is intended to be indicative of the outcomes that might be achieved given a particular research objective while keeping in mind the need to be transparent and to retain as much data as possible. Of course there may well be a need for further processing of the above data in order to build a specific predictive model. For instance, researcher or practitioner interest may be in enhancement-type projects - in that case only those projects with a value of "Enhancement" for 'Development Type' would likely be considered. Even if that were the case, however, the above process would have ensured that as many of these relevant observations as possible were available for such an analysis, along with a range of potentially influential variables. Assuming that the retained data does indeed reflect one or more underlying models, such outcomes should increase the likelihood of robust models being produced.

\section{ACKNOWLEDGEMENT}

We thank the ISBSG for providing the data that enabled this work to be carried out.

\section{REFERENCES.}

[1] Kitchenham, B., E. Mendes and G.H. Travassos, "A systematic review of cross- vs. within-company cost estimation studies", Proc. 10th Int/ Conf Empirical Assessment in Soft Eng 2006.

[2] MacDonell, S.G., and M.J. Shepperd, "Comparing local and global software effort estimation models reflections on a systematic review", Proc. 1st Intl Symp Empirical Soft Eng \& Measmt 2007, 401-409.

[3] Experience Pro - Software Technology Transfer Finland, http://www.sttf.fi/eng/indexEnglish.htm

[4] International Software Benchmarking Standards Group, http://www.isbsg.org

[5] Briand, L.C., K. El Emam, D. Surmann, I. Wieczorek and K. Maxwell, "An assessment and comparison of common software cost estimation modeling techniques", Proc. 21st Int/ Conf Soft Eng 1999, 313-322.

[6] Jeffery, R., M. Ruhe and I. Wieczorek, "Using public domain metrics to estimate software development effort", Proc. 7th Intl Soft Metrics Symp 2001, 16-27.

[7] Sentas, P., L. Angelis, I. Stamelos and G. Bleris, "Software productivity and effort prediction with ordinal regression", Information and Software Technology 47, 2005, 17-29.

[8] Mendes, E., C. Lokan, R. Harrison and C. Triggs, "A replicated comparison of cross-company and withincompany effort estimation models using the ISBSG database", Proc. 7th Intl Soft Metrics Symp 2005.

[9] Cuadrado-Gallego, J.J., M.-A. Sicilia, M. Garre and D. Rodriguez, "An empirical study of process-related attributes in segmented software cost-estimation relationships", Journal of Systems \& Software 79, 2006, 353-361.

[10] Abran, A., I. Ndiaye and P. Bourque, "Evaluation of a black-box estimation tool: a case study", Software Process Improvement and Practice 12, 2007, 199-218.

[11] Adalier, O., A. Uğur, S. Korukoğlu and K. Ertaş, "A new regression based software cost estimation model using power values", IDEAL 2007, Lecture Notes in Computer Science 4881, 2007, 326-334.

[12] Gencel, C., and L. Buglione, "Do different functionality types affect the relationship between software functional size and effort?", Proc. 2007 Int/ Workshop Soft Measmt, 2007, 235-246.

[13] Xia, W., D. Ho and L.F. Capretz, "Calibrating function points using neuro-fuzzy technique", Proc. $21^{\text {st }}$ Intl Forum COCOMO and Softw Cost Modeling, 2006.

[14] Pendharkar, P.C., J.A. Rodger and G.H. Subramanian, "An empirical study of the Cobb-Douglas production function properties of software development effort", Information and Software Technology, In Press.

[15] Jiang, Z., P. Naudé and B. Jiang, "The effects of software size on development effort and software quality", Proc. World Academy Sci, Eng and Tech 23 2007, 363-367.

[16] Everitt, B.S., and G. Dunn, Applied Multivariate Data Analysis, Second Edition, 2001.

[17] Twala, B., M. Cartwright and M. Shepperd, "Comparison of various methods for handling incomplete data in software engineering databases", Proc. Intl Symp Empirical Soft Eng 2005, 105-114.

[18] P. Jonsson and C. Wohlin, "An evaluation of $k$-nearest neighbour imputation using Likert data", Proc. 10th Intl Soft Metrics Symp 2004, 108-118

[19] Li, J., A. Al-Emram and G. Ruhe, "Impact analysis of missing values on the prediction accuracy of analogy based software effort estimation method AQUA", Proc. 1st Intl Symp Empirical Soft Eng \& Measmt 2007, 126-135. [20] Liebchen, G., B. Twala, M. Shepperd, M. Cartwright and M. Stephens, "Filtering, robust filtering, polishing: techniques for addressing quality in software data", Proc. 1st Intl Symp Empirical Soft Eng \& Measmt 2007, 99106.

[21] Weisberg, S., Applied Linear Regression, John Wiley \& Sons. New York, 1985. 